\title{
Evaluation of Growth and Cereulide Production by Bacillus cereus Isolated from Cooked Rice
}

\author{
Damilola O. Seyi-Amole ${ }^{\mathrm{a}}$, Abiodun A. Onilude ${ }^{\mathrm{a}}$, Dasari S. Rani ${ }^{\mathrm{b}}$, And Prakash \\ M. HALAMI ${ }^{\mathrm{b}}$ \\ a Microbial Physiology and Biochemistry Laboratory, Department of Microbiology, University of Ibadan, \\ Ibadan, Nigeria \\ b Microbiology and Fermentation Technology Department, CSIR-Central Food Technological Research \\ Institute, Mysore 570 020, India \\ ${ }^{*}$ Corresponding author \\ doseyiamole@gmail.com \\ TEL: $+234-708-139-2027$
}

Received: 25 March 2018; Published online: 18 April 2020

\begin{abstract}
Conditions influencing Bacillus cereus growth and cereulide production, such as temperature and $\mathrm{pH}$, were evaluated at varying incubation periods. The growth and cereulide production at different temperatures and $\mathrm{pH}$ values ranging from 10 to $40{ }^{\circ} \mathrm{C}$ and 5.0 to 8.5 , respectively showed that the temperature from 20 to $30{ }^{\circ} \mathrm{C}$ and at $\mathrm{pH}$ from 6.0 to 7.0 gave the optimum growth and cereulide production by $B$. cereus SA105. $\mathrm{pH}$ below 6.0 resulted in reduced growth and cereulide production. Cereulide production increased along with the incubation period, and the maximum cereulide titre $(\mathrm{ng} / \mathrm{mL})$ of $1219.1 \pm 8.90$ was obtained after 6 days of incubation at $30^{\circ} \mathrm{C}$ and $\mathrm{pH} 6.5$ under static conditions. There was no quantifiable toxin at incubation temperatures of 10 and $40{ }^{\circ} \mathrm{C}$ by $B$. cereus SA105. This work further reveals that $B$. cereus growth and cereulide production was significantly affected by temperature and $\mathrm{pH}$ in relation to the incubation period. Furthermore, the findings of this study will serve as a means for reducing the diversity of the emetic toxin-producing $B$. cereus population in food and food products, thus preventing food poisoning.
\end{abstract}

Keywords: Bacillus cereus; Growth; Cereulide; pH; Temperature; Incubation period

\section{Introduction}

Bacillus cereus, a Gram-positive, rod-shaped, beta haemolytic, endemic soil-dwelling bacterium is a common cause of food poisoning around the world (Turnbull, 1996). Episodes of $B$. cereus food poisoning occur sporadically worldwide, resulting from ingestion of contaminated food containing the bacteria, which multiply in high levels (McKillip, 2000). Basically, $B$. cereus is the etiological agent of two distinct types of gastrointestinal disorders, the diarrhea and emetic syndromes. The two types of food- borne diseases are caused by toxins: the diarrhea type by protein toxins which are thermolabile and formed in the intestinal tract of the host by the growing organism (enterotoxin) and the emetic type by a cyclic peptide (non-protein) toxin that is thermostable and pre-formed in food (emetic toxin) (Agata et al., 1994; Agata, Ohta, Mori, \& Isobe, 1995; Granum, 2007; Jay, Loessner, \& Golden, 2005).

The emetic syndrome was first identified in the 1970s and was associated with the consumption of fried rice (Kramer \& Gilbert, 1989). This syndrome is an intoxication caused by $B$. 
136 | Seyi-Amole et al.

cereus emetic toxin, called cereulide which is secreted in foods before ingestion. The toxin is a ring shaped, dodecadepsipeptide consisting of four acids, repeating three times and oxy acids (Granum \& Lund, 1997). Jay (1996) reported that the disease is more acute than the diarrhea syndrome with an incubation time of 1-5 hrs, manifesting nausea, vomiting (emesis) and sometimes diarrhea which lasts for 6-24 hrs (EhlingSchulz, Fricker, \& Scherer, 2004). However, for the transmission of this type of $B$. cereus food poisoning, the infective dose of $B$. cereus in implicated food is $10^{5}-10^{8}$ cell/g of food (Wijnands, Dufrenne, Rombouts, In't Veld, \& Van Leusden, 2006).

Furthermore, several studies have indicated that only a minority of $B$. cereus isolates may produce cereulide (Agata, Ohta, \& Mori, 1996; Mikami et al., 1994; Pirttijärvi, Andersson, Scoging, \& Salkinoja-Salonen, 1999). Yokoyama et al. (1999) suggested that more than $90 \%$ of food poisoning caused by $B$. cereus is of the emetic type in countries of the Far East. This may be partly due to the wide consumption of rice, which is a well-known food vehicle for the emetic toxin. Lund, De Buyser, and Granum (2000) reported the toxin produced by $B$. cereus, cereulide, as the most dangerous toxin to human health responsible for the deaths of young healthy individuals. The prolific growth of $B$. cereus in various food sources and its ability to produce heat stable, non-protein toxin calls for urgency to the microbiological quality and safety of food products. Several studies have been done on the effect of environmental factors on the growth and cereulide production of $B$. cereus (Agata et al., 1996; Agata, Ohta, \& Yokoyama, 2002; Finlay, Logan, \& Sutherland, 2002a, 2002b). However, it could be of interest to study the effect of environmental factors in relation to time for the growth and cereulide production of emetic toxinproducing $B$. cereus. In this article, we compare and assess the effects of temperature and $\mathrm{pH}$ on growth and cereulide production of $B$. cereus at different days of incubation.

\section{Materials and Methods}

\subsection{Microorganism}

The emetic toxin-producing strain of Bacillus cereus SA105 isolated from cooked rice in Ibadan, Oyo State, Nigeria was used for this study.

\section{$2.2 \quad$ Effect of environmental factors on $B$. cereus growth}

\section{Effect of temperature on B. cereus growth}

The effect of temperature on the growth of the toxigenic $B$. cereus strain was determined using the method of From, Pukall, Schumann, Hormazabal, and Granum (2005) and Chorin, Thuault, Cleret, and Bourgeois (1997). $10 \mathrm{~mL}$ of sterile Tryptone Soy Broth was inoculated with a suspension of vegetative cells of $B$. cereus to achieve a concentration of $10^{3} \mathrm{CFU} / \mathrm{mL}$. The tubes were sealed with paraffin film to avoid evaporation and concentration of the liquid medium at higher temperatures. After inoculation of 3 replica tubes, for each condition tested, media was then incubated for $1,2,4,6,8$ and 10 days at temperatures of $10,20,30$ and $40{ }^{\circ} \mathrm{C}$.

\section{Effect of pH on $B$. cereus growth}

The modified method of Chorin et al. (1997) was used to determine the effect of $\mathrm{pH}$ on the growth of the toxigenic isolate. Culture of the toxigenic $B$. cereus isolate was performed in Tryptone Soy Broth. $10 \mathrm{~mL}$ of sterile media was inoculated with a suspension of vegetative cells of $B$. cereus to achieve a concentration of $10^{3} \mathrm{CFU} / \mathrm{mL}$. The media was buffered with M.E.S (2-(N-morpholino) ethane-sulfonic acid, for $\mathrm{pH}$ ranging from 5.0 to 6.7 and with M.O.P.S (3-(N-morpholino) propane-conse-sulfonic acid, from 6.5 to 7.9 . The $\mathrm{pH}$ was adjusted using $0.1 \mathrm{M}$ of $\mathrm{HCl}$ or $\mathrm{NaOH}$. Precise volumes of sterile $\mathrm{HCl}$ or $\mathrm{NaOH}$ were added respectively for $\mathrm{pH}: 5.0,5.5$, $6.0,6.5,7.0,7.5,8.0,8.5$. The adjusted media from $\mathrm{pH} 5.0$ to 8.5 was inoculated as previously described using 3 replicates for each condition 
tested. The different media were later incubated at $30{ }^{\circ} \mathrm{C}$ for $24 \mathrm{hrs}$.

\subsection{Effect of environmental factors on cereulide production}

\section{Effect of $B$. cereus growth and incubation temperature on cereulide production}

Tryptone Soy Broth (100 mL) was inoculated with $10^{3} \mathrm{CFU} / \mathrm{mL}$ of $B$. cereus $\mathrm{SA} 105$ overnight culture. Triplicate cultures were thereafter incubated at temperatures of $10,20,30$, and 40 ${ }^{\circ} \mathrm{C}$; static condition and agitation speed of 150 rpm. Following incubation, $1 \mathrm{~mL}$ was taken from each culture tube for serial dilution and the viable count was determined. Cereulide was extracted with pentane, and analysed using HPLC-MS after 1, 2, 4 and 6 days of incubation (Haggblom, Apetroaie, Andersson, \& SalkinojaSalonen, 2002).

\section{Effect of $\mathrm{pH}$ on cereulide production}

The pH (5.0-8.5) of Tryptone Soy Broth was adjusted and inoculated as previously described using 3 replicates for each condition tested. The different media were later incubated at $30^{\circ} \mathrm{C}$ at $150 \mathrm{rpm}$. Cereulide was extracted with pentane, and analysed using HPLC-MS after 1, 2, 4 and 6 days of incubation.

\subsection{Preparation of cell extracts}

Incubated cultures were autoclaved $\left(120{ }^{\circ} \mathrm{C} ; 19\right.$ mins) to destroy heat-labile proteins and other substances. The liquid cultures were extracted twice, each time with an equal volume of pentane for $1 \mathrm{hr}$ with mild agitation $(25 \mathrm{rpm})$ in vertical motion and after shaking the tubes were frozen. Organic phase layer was then separated from the aqueous phase layer in a smaller test tube. The combined pentane phases were evaporated to dryness under a stream of nitrogen and the residue was dissolved in $1 \mathrm{~mL}$ of methanol (Andersson, Mikkola, Helin, Andersson, \& SalkinojaSalonen, 1998).

\section{$2.5 \quad$ HPLC-MS analysis}

High-performance liquid chromatography (HPLC)-MS analysis was performed on a Waters 2695 Separation Module HPLC equipped with a $\mathrm{C}_{8}$ column (250 x $4.6 \mathrm{~mm}, 5 \mu \mathrm{m}$ Waters) and a solvent made up to $95 \%$ Acetonitrile, 4.9 $\% \mathrm{H}_{2} \mathrm{O}$, and $0.1 \%$ Trifluoroacetic acid at a flow rate of $0.15 \mathrm{~mL} / \mathrm{min}$, with sample injection monitored with a Diode array detector. A full mass spectrum was recorded from 500 to $1,300 \mathrm{~m} / \mathrm{z}$ in positive electron spray mode (ESI \pm ). The total ion chromatogram was smoothed with Gaussian function. Valinomycin (Sigma) was used as the standard compound for quantification of cereulide. To quantify cereulide and valinomycin absorbance, Integrated Extracted Ion Current (EIC) chromatograms with ion ranges $(\mathrm{m} / z)$ of $1,170.5$ to $1,193.5$ for cereulide and $1,128.5$ to 1,151.0 for valinomycin targeting the $\mathrm{NH}^{ \pm}$and $\mathrm{K}^{ \pm}$adducts respectively, were used. Calibration curves extrapolated from integrated peak areas were plotted to calculate cereulide amounts via linear regression (Haggblom et al., 2002).

\section{Results and discussion}

\subsection{Effect of temperature on $B$. cereus growth}

he $B$. cereus SA105 growth profile at varying temperatures $\left(10-40{ }^{\circ} \mathrm{C}\right)$ is shown in Figure 1, with maximum and minimum growth recorded at 30 and $10^{\circ} \mathrm{C}$ after day 6 and 10 of incubation, respectively. The optimum temperature $\left(30^{\circ} \mathrm{C}\right)$ for $B$. cereus SA105 recorded is in accordance with the report of previous authors who observed the optimum temperature for the growth of $B$. cereus to be between $30-37{ }^{\circ} \mathrm{C}$ (European Food Safety Agency, 2005; Nguyen-The, Carlin, \& Guinebretière, 2003). Similar to the present observation, Pielaat, Fricker, Nauta, and Van Leusden (2005), Carlin et al. (2006) and Wijnands et al. (2006) also reported that emetic toxinproducing $B$. cereus are found to be mesophilic in nature. The implication is that refrigeration will considerably increase the lag time and reduce the growth of emetic toxin-producing strains of B. cereus. 


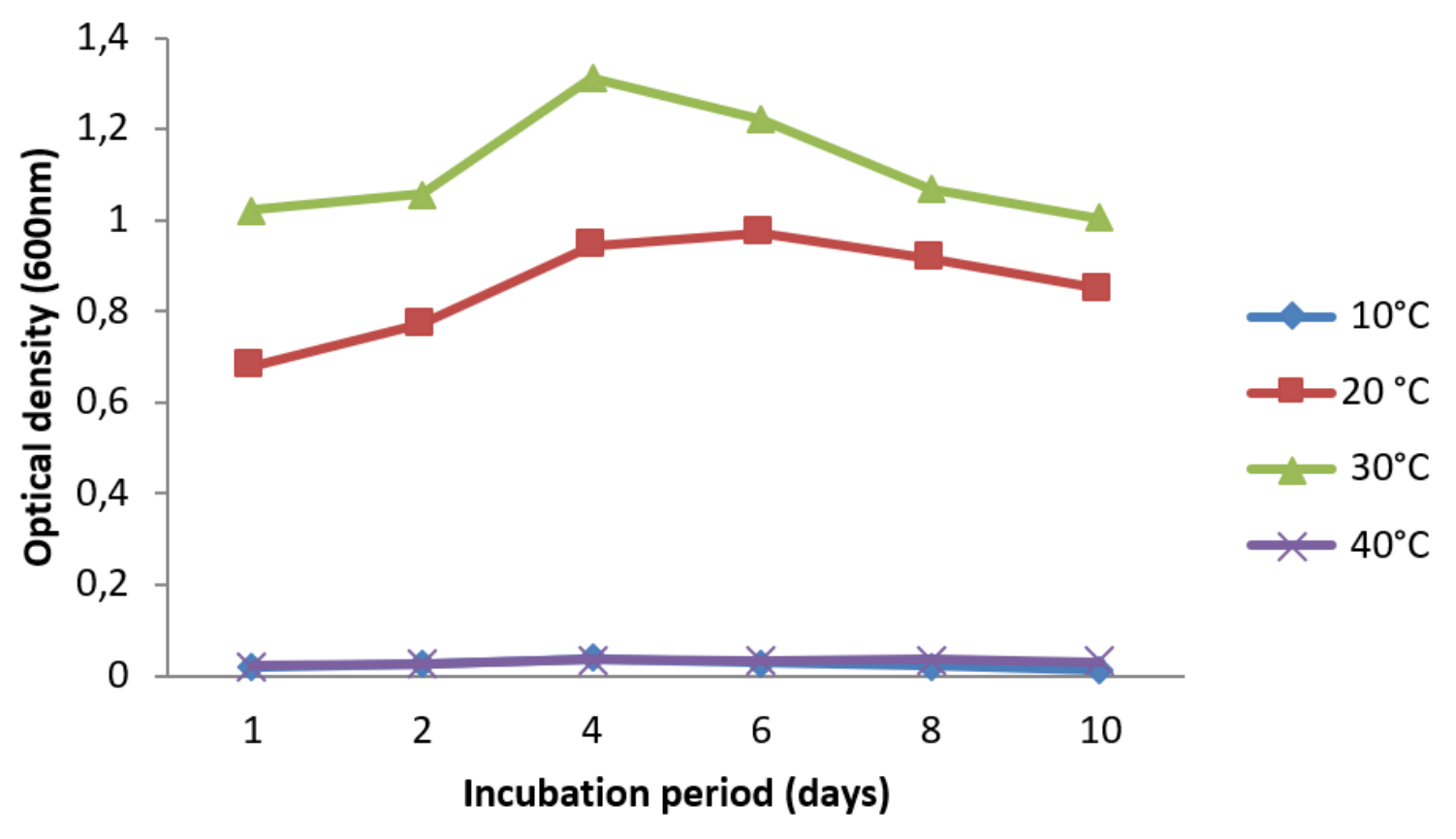

Figure 1: Effect of temperature on the growth of B. cereus SA105. Suspension of vegetative cells of the selected strain grown in Tryptone Soy Broth at varying incubation temperature and period (days) under static conditions. The values are presented as the mean \pm SEM, $n=3$

\subsection{Effect of $\mathrm{pH}$ on $B$. cereus growth}

Results of the effect of $\mathrm{pH}$ on the growth of $B$. cereus SA105 are shown in Figure 2. The optimum $\mathrm{pH}$ for growth of $B$. cereus $\mathrm{SA} 105$ was $\mathrm{pH}$ 6.5. This was followed by $\mathrm{pH} 6.0$ which gave the second highest absorbance while the least growth was observed at $\mathrm{pH}$ 5.0. The growth decreased with $\mathrm{pH}$ below 6.0 and above 8.5. Evaluation of the effect of $\mathrm{pH}$ on the growth rate of the emetic strain of $B$. cereus in this study revealed that it grew best from $\mathrm{pH} 6.0$ to 7.0 and that it is not acid-tolerant. It is important to note that, at this optimum $\mathrm{pH}$ (6.0-7.0), the growth rate will be increased and lag time will be shorter (Benedict, Partridge, Wells, \& Buchanan, 1993; Martinez, Borrajo, Franco, \& Carballo, 2007). From the result obtained, it is indicated that $\mathrm{pH}$ below 5.5 was inhibitory to the strain thus, acidification is sufficient to prevent the growth of emetic strains of $B$. cereus during a longer storage period. This is useful in extending the shelf life and safety of processed foods but the significance to food protection is minimal since very few foods have such high acidity (Lindsay, Brozel, Mostert, \& von Holy, 2000).

\subsection{Effect of $B$. cereus growth and incubation temperature on cereulide production}

The result (Figure 3) of viable counts and cereulide concentration at different incubation temperatures under static conditions revealed that $B$. cereus SA105 grew at all the incubation temperatures after 4 days of incubation. The highest cereulide concentration of $762.0 \pm 2.28 \mathrm{ng} / \mathrm{mL}$ and viable count of $6.3 \pm 0.23$ $\log _{10} \mathrm{CFU} / \mathrm{mL}$ was recorded by $B$. cereus $\mathrm{SA} 105$ at $30^{\circ} \mathrm{C}$ after 4 days. Increased temperature 


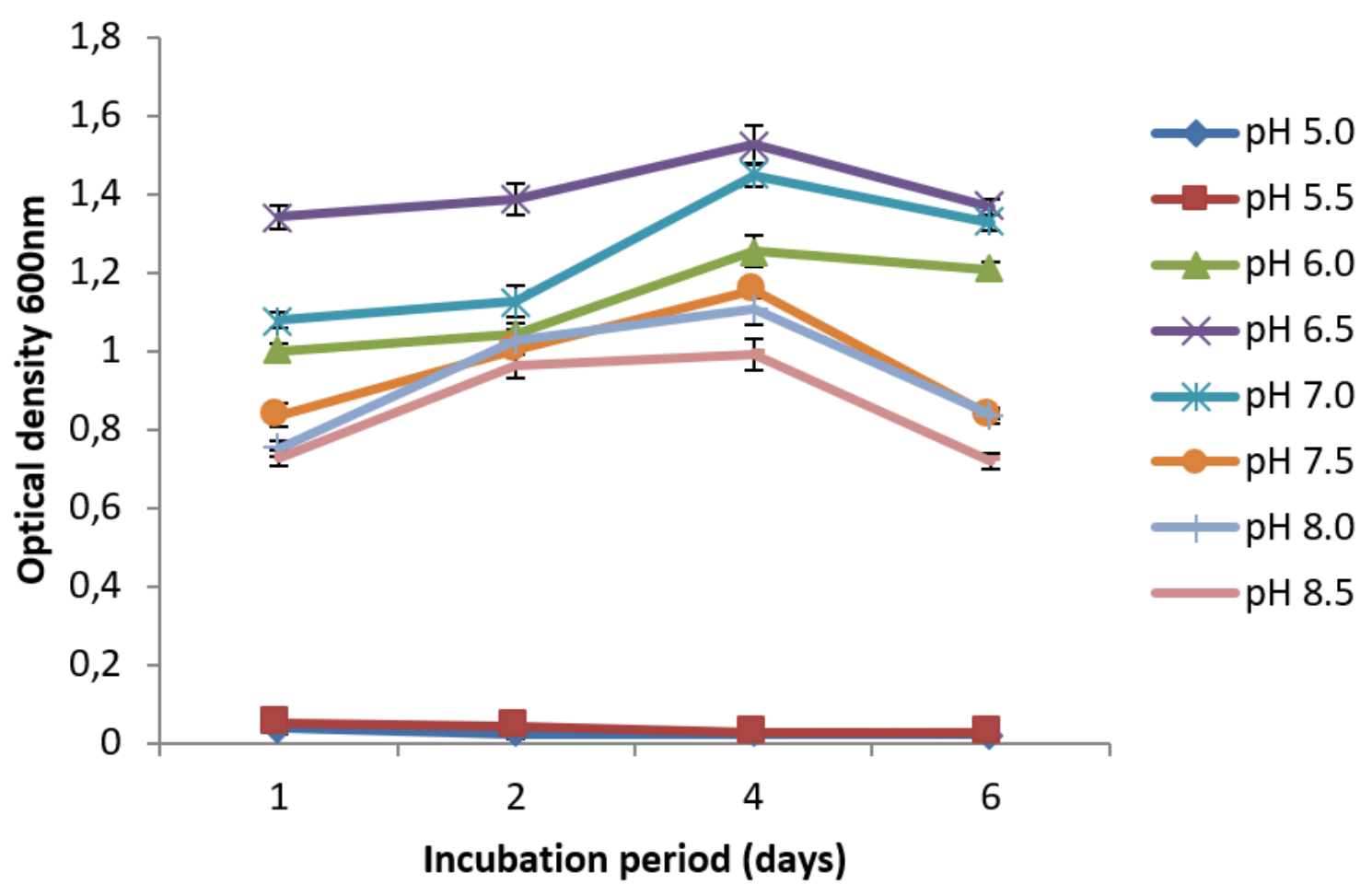

Figure 2: Effects of $\mathrm{pH}$ on the growth of B. cereus SA105. Suspension of vegetative cells of the selected strain grown in Tryptone Soy Broth, incubated at $30{ }^{\circ} \mathrm{C}$ and, at varying $\mathrm{pH}$ and incubation times (days) under static conditions. The values are presented as the mean $\pm \mathrm{SEM}, \mathrm{n}=3$

(above $10^{\circ} \mathrm{C}$ ) led to an increase in the growth of the test strain which influenced the production of cereulide. However, the mesophilic temperature has been previously observed to favor cereulide production in emetic strains of $B$. cereus (Dommel, Luecking, Scherer, \& Ehling-Schulz, 2011). In our study, no quantifiable amount of cereulide was produced at 10 and $40{ }^{\circ} \mathrm{C}$ although the emetic strain was able to grow at these temperatures. In contrast, quantifiable amount of cereulide was produced in $B$. weihenstephanensis at $8-10{ }^{\circ} \mathrm{C}$ (Guerin et al., 2017). It has been previously reported that the production of cereulide below $10{ }^{\circ} \mathrm{C}$ does not seem possible and that temperatures above $37{ }^{\circ} \mathrm{C}$ also do not permit cereulide production (Finlay, Logan, \& Sutherland, 2000, 2002a, 2002b; Jaaskelainen, Haggblom, Andersson, \& Salkinoja-Salonen, 2004). The lack of quantifiable cereulide production by
B. cereus at 10 and $40^{\circ} \mathrm{C}$ implies that foods held for long periods at $\leq 10^{\circ} \mathrm{C}$ and at raised temperatures are unlikely to be a risk for emetic food poisoning.

At $30{ }^{\circ} \mathrm{C}$ under static conditions, the growth curve of the tested strain (Fig. 4) attained its peak after day 4 with a mean viable count $\left(\log _{10} \mathrm{CFU} / \mathrm{mL}\right)$ of $6.3 \pm 0.23$. Cereulide production was first detectable after day 1 of incubation with the mean toxin titre of $117.5 \pm 4.45$ $\mathrm{ng} / \mathrm{mL}$ and gradually a maximum mean titre of $1131.7 \pm 0.90 \mathrm{ng} / \mathrm{mL}$ was attained after 6 days of incubation. In this study, the emetic strain of $B$. cereus analyzed started its exponential growth from day 2 to day 4 with a slight drop after day 4 , probably from depletion of nutrients. Interestingly, cereulide was detectable after $24 \mathrm{hrs}$ at $30{ }^{\circ} \mathrm{C}$ with an amount exceeding the minimum acute toxic level of cereulide (10 ng/g) as quanti- 


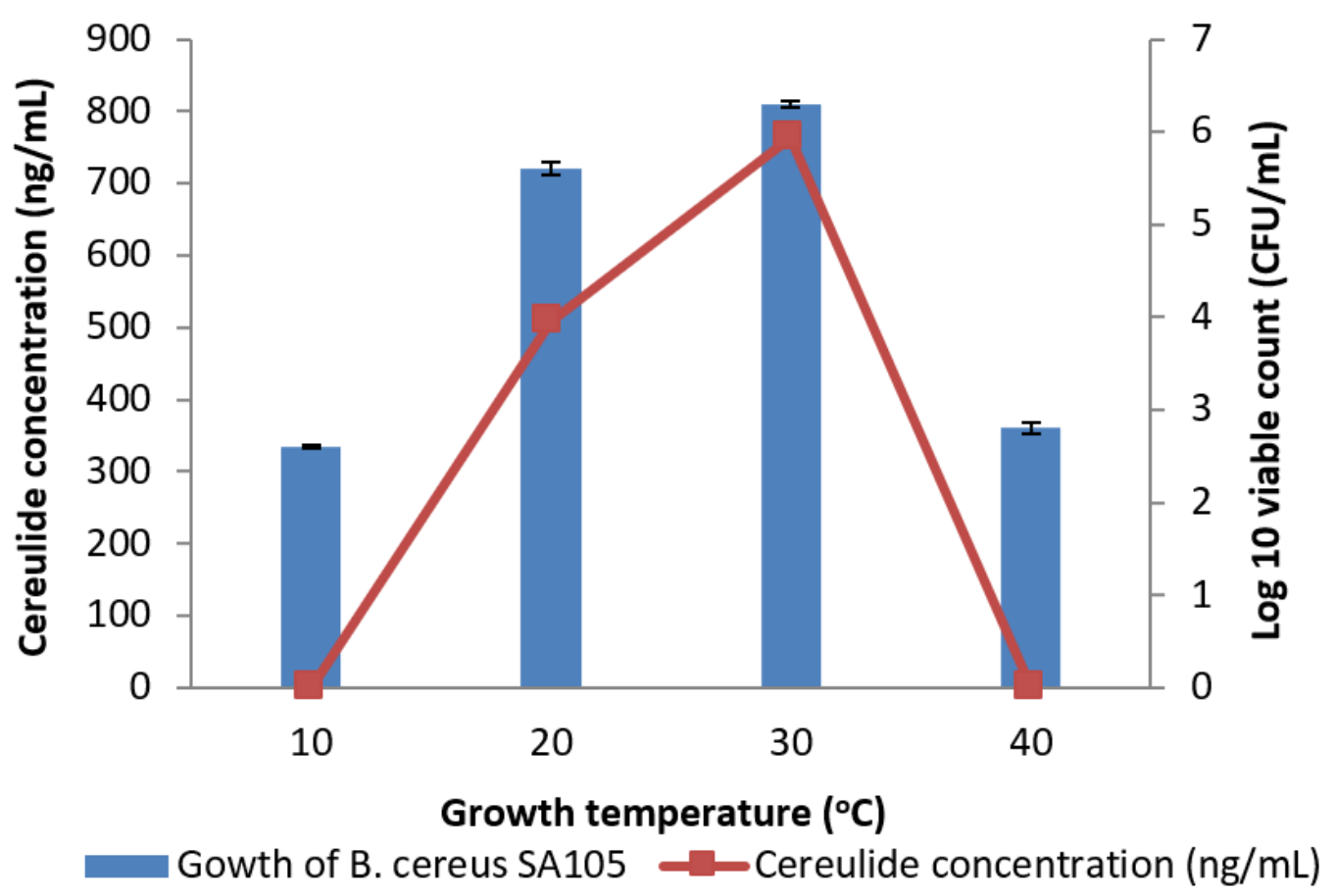

Figure 3: Effects of $B$. cereus growth and incubation temperatures on cereulide (ng/mL) production. The viable count was determined and cereulide was quantified using HPLC-MS after 4 days of incubation under static conditions. The values are presented as the mean \pm SEM, $n=3$

fied by Agata et al. (2002) in samples implicated in different outbreaks. Other studies have revealed that $20-30{ }^{\circ} \mathrm{C}$ is the optimal temperature for cereulide production and this supports the findings of the study (Thorsen, Budde, Henrichsen, Martinussen, \& Jakobsen, 2009). The difference in the optimal temperature is influenced mainly by the bacterial growth rate and composition of the media or food (Agata et al., 2002; Rajkovic et al., 2006). Cereulide production in relation to temperature and time was analyzed in this study and it was discovered that the highest cereulide concentration was observed at the end of the growth period, which was between day 6-8. This agrees with the previous work of Haggblom et al. (2002) who reported that cereulide production is growth phase-dependent and that maximum cereulide was recorded at the end of the growth period. Hence, the incubation pe- riod (storage time) plays an important role in cereulide production since it was observed that cereulide production increased during the late stationary phase.

The effect of agitation on growth and cereulide production was established at $30^{\circ} \mathrm{C}$ and $150 \mathrm{rpm}$ for 10 days. The maximum mean viable count $\left(\log _{10} \mathrm{CFU} / \mathrm{mL}\right)$ recorded was $8.1 \pm 0.31$ (day 4 ) which was higher than the non-agitated broth at $30{ }^{\circ} \mathrm{C}$. Cereulide was detectable after day 1 of incubation with a mean toxin titre of $317.5 \pm 2.99$ $\mathrm{ng} / \mathrm{mL}$ and the maximum mean toxin titre of $1670.7 \pm 7.43 \mathrm{ng} / \mathrm{mL}$ (day 8) was recorded (Fig. $5)$. The role of aeration in cereulide production cannot be underestimated, since the production of cereulide is greatly inhibited by a reduction in atmospheric oxygen. Oxygen acts as a terminal electron acceptor for oxidative reactions in providing energy for all cellular activities. Aeration 


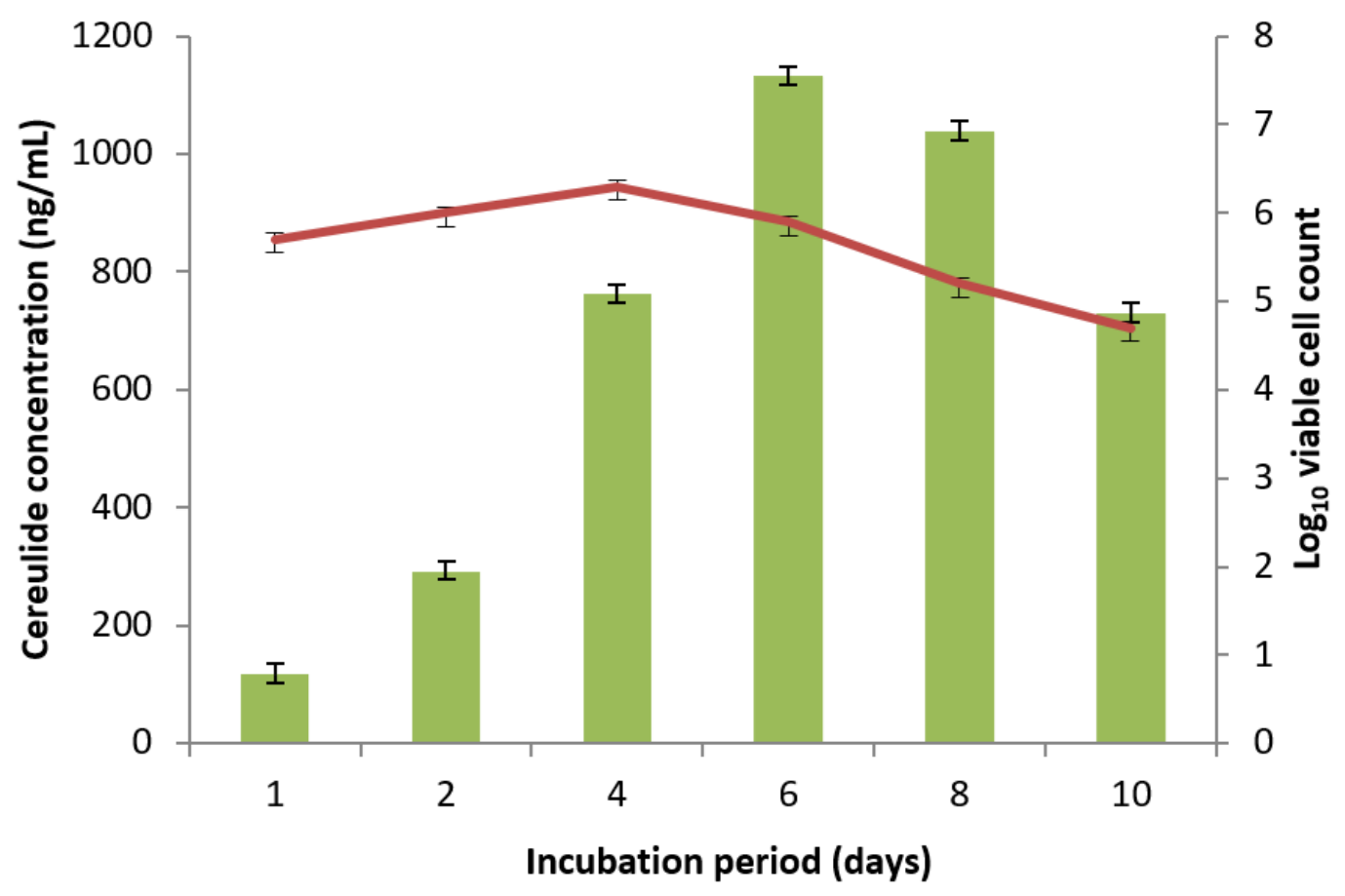

\section{Cereulide concentration $(\mathrm{ng} / \mathrm{mL})$ Growth of B.cereus SA105}

Figure 4: Production of cereulide $(\mathrm{ng} / \mathrm{mL})$ by B. cereus $\mathrm{SA} 105$ at $30{ }^{\circ} \mathrm{C}$ under static conditions. Vegetative cells of $B$. cereus SA105 were grown in broth and incubated at $30{ }^{\circ} \mathrm{C}$ under static conditions. The viable count was determined and cereulide was quantified using HPLC-MS after different incubation periods. The values are presented as the mean \pm SEM, $n=3$

influences the mixing and nutrient availability in shaking flasks (do Nascimento \& Martins, 2004). Thus, oxygen is regarded as a stimulating factor in cereulide production (Agata et al., 2002; Finlay et al., 2002b). In contrast, Rajkovic et al. (2006) and Shaheen et al. (2006) reported an inhibitory effect of oxygen on cereulide production.

\subsection{Effect of $\mathrm{pH}$ on cereulide production}

The result (Table 1 ) of cereulide production in broth inoculated with $B$. cereus SA105 at different $\mathrm{pH}$ values incubated for 6 days. At $\mathrm{pH} 5.0$ cereulide was not detected until day 4 while at pH 5.5 cereulide was detected at day 2. Quantifiable cereulide concentration was recorded after day 1 in $\mathrm{pH}$ ranging from 6.0-8.5. However, the highest mean toxin titre of $1219 \pm 8.9 \mathrm{ng} / \mathrm{mL}$ was produced at $\mathrm{pH} 6.5$ followed by $\mathrm{pH} 6.0$ reaching a mean toxin titre of $970.6 \pm 1.18 \mathrm{ng} / \mathrm{mL}$ after 6 days of incubation. Acidic $\mathrm{pH}$ inhibited cereulide production by the emetic strain of $B$. cereus in this study. In a previous study, Agata et al. (2002) reported that the addition of dressings like mayonnaise, vinegar or ketchup to rice for the purpose of acidification decreased $B$. cereus growth in these foods and cereulide produced was

$$
\text { IJFS | April 2020 | Volume } 9 \text { | pages 135-145 }
$$




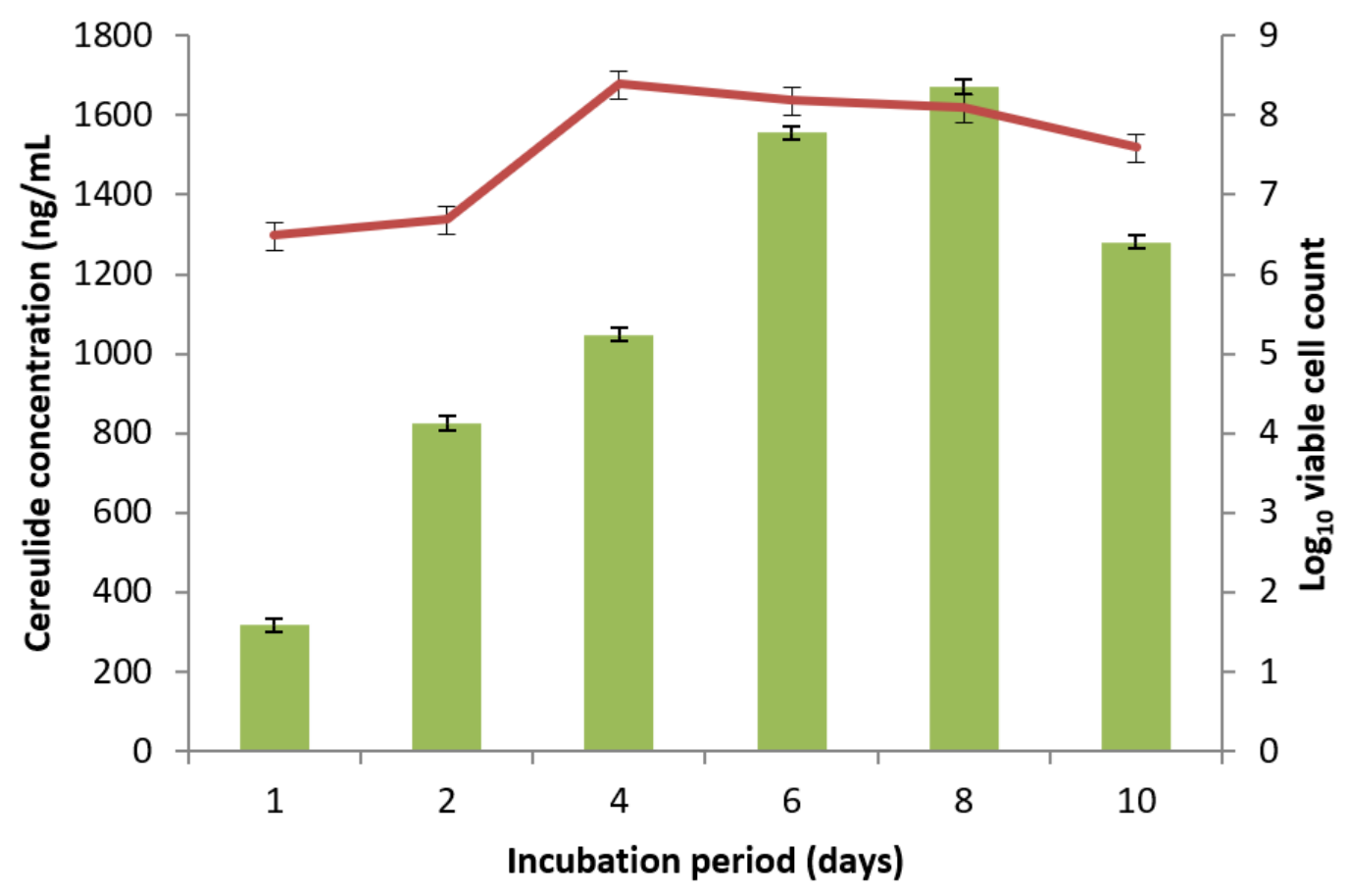

Figure 5: Production of cereulide $(\mathrm{ng} / \mathrm{mL})$ by $B$. cereus SA105 at $30{ }^{\circ} \mathrm{C}$ and $150 \mathrm{rpm}$. Vegetative cells of $B$. cereus SA105 were grown in broth and incubated at $30^{\circ} \mathrm{C}$ and $150 \mathrm{rpm}$. The viable count was determined and cereulide was quantified using HPLC-MS after different incubation periods. The values are presented as the mean \pm SEM, $\mathrm{n}=3$

Table 1: Effect of $\mathrm{pH}$ on cereulide production $(\mathrm{ng} / \mathrm{mL})$ by B. cereus $\mathrm{SA} 105$

\begin{tabular}{ccccc}
\hline & \multicolumn{3}{l}{ Incubation Period (days)/ Cereulide production $(\mathrm{ng} / \mathrm{mL})$} \\
\cline { 2 - 5 } $\mathrm{pH}$ & 1 & 2 & 4 & 6 \\
\hline 5.0 & $\mathrm{ND}$ & $\mathrm{ND}$ & $15.4 \pm 2.28^{g}$ & $24.4 \pm 0.90 \mathrm{~g}^{ \pm}$ \\
5.5 & $\mathrm{ND}$ & $31.7 \pm 0.30^{g}$ & $39.4 \pm 4.90^{f}$ & $44.8 \pm 3.50^{f}$ \\
6.0 & $115.6 \pm 3.55^{d}$ & $476.2 \pm 1.15^{c}$ & $732.2 \pm 4.48^{b}$ & $1070.6 \pm 1.18^{b}$ \\
6.5 & $295.3 \pm 1.95^{b}$ & $521.2 \pm 9.95^{a}$ & $828.4 \pm 6.25^{a}$ & $1219.1 \pm 8.90^{a}$ \\
7.0 & $108.5 \pm 4.75^{a}$ & $431.5 \pm 2.75^{b}$ & $673.3 \pm 4.75^{c}$ & $1028.4 \pm 2.70^{c}$ \\
7.5 & $94.1 \pm 2.75^{c}$ & $212.5 \pm 2.24^{d}$ & $375.0 \pm 4.75^{d}$ & $653.2 \pm 5.03^{d}$ \\
8.0 & $89.4 \pm 6.20^{d}$ & $178.3 \pm 1.18^{e}$ & $317 \pm 2.50^{c}$ & $543.5 \pm 0.02^{e}$ \\
8.5 & $45.0 \pm 1.90^{e}$ & $94.9 \pm 9.65^{f}$ & $124.5 \pm 2.80^{e}$ & $256.7 \pm 0.85^{e}$ \\
\hline
\end{tabular}

The values are presented as the mean $\pm \mathrm{SEM}, \mathrm{n}=3 .{ }^{ \pm}$Values with different letters in the same column indicate a significant difference $(\mathrm{P} \leq 0.05)$ using Duncan's Multiple Range Test. ND: Not Detected 
below $0.01 \mu \mathrm{g} / \mathrm{g}$, which is similar to the effect of acidic $\mathrm{pH}$ in this study. This agrees with the work of Wong and Chen (1988) who reported the effect of $\mathrm{pH}$ on $B$. cereus growth and the experimental result of its growth and emetic toxin production on Brain Heart Infusion (BHI) bouillon and food products. Hence, a possible strategy to prevent growth and cereulide production by emetic strains of $B$. cereus is through the acidification of food.

\section{Conclusions}

This extensive study shows that the various environmental factors analyzed (temperature, $\mathrm{pH}$, aeration, and incubation period) played an important role in influencing growth and cereulide production by the emetic strains of $B$. cereus. Hence, the findings of this study will serve as a means for reducing the diversity of emetic toxinproducing $B$. cereus populations able to multiply in food and food products thus preventing food poisoning.

\section{Acknowledgements}

This study was supported by the INSA-JRD TATA Fellowship administered by Centre for International Co-operation in Science (CICS), Chennai.

We are grateful to the Department of Microbiology and Fermentation Technology, CSIR-Central Food Technological Institute, Mysore, India for providing help with cereulide evaluation.

\section{References}

Agata, N., Mori, M., Ohta, M., Suwan, S., Ohtani, I., \& Isobe, M. (1994). A novel dodecadepsipeptide, cereulide, isolated from Bacillus cereus causes vacuole formation in hep-2 cells. Fems Microbiology Letters, 121 (1), 31-34. doi:10.1016/0378-1097(94) 90141-4

Agata, N., Ohta, M., \& Mori, M. (1996). Production of an emetic toxin, cereulide, is associated with a specific class of Bacillus cereus. Current microbiology, 33(1), 67-69.
Agata, N., Ohta, M., Mori, M., \& Isobe, M. (1995). A novel dodecadepsipeptide, cereulide, is an emetic toxin of Bacillus cereus. Fems Microbiology Letters, $129(1)$, 17-19.

Agata, N., Ohta, M., \& Yokoyama, K. (2002). Production of Bacillus cereus emetic toxin (cereulide) in various foods. International Journal of Food Microbiology, 73(1), 2327. doi:10.1016/S0168-1605(01)00692-4

Andersson, M. A., Mikkola, R., Helin, J., Andersson, M. C., \& Salkinoja-Salonen, M. (1998). A novel sensitive bioassay for detection of Bacillus cereus emetic toxin and related depsipeptide ionophores. Applied and Environmental Microbiology, 64(4), 1338 1343.

Benedict, R. C., Partridge, T., Wells, D., \& Buchanan, R. L. (1993). Bacillus cereus - aerobic growth-kinetics. Journal of Food Protection, 56(3), 211-214. doi:10.4315/ 0362-028X-56.3.211

Carlin, F., Fricker, M., Pielaat, A., Heisterkamp, S., Shaheen, R., Salonen, M. S., .. . EhlingSchulz, M. (2006). Emetic toxin-producing strains of bacillus cereus show distinct characteristics within the Bacillus cereus group. International Journal of Food Microbiology, 109(1-2), 132-138. doi:10.1016/ j.ijfoodmicro.2006.01.022

Chorin, E., Thuault, D., Cleret, J. J., \& Bourgeois, C. M. (1997). Modelling Bacillus cereus growth. International Journal of Food Microbiology, 38(2-3), 229-234. doi:10.1016/S0168-1605(97)00110-4

do Nascimento, W. C. A., \& Martins, M. L. L. (2004). Production and properties of an extracellular protease from thermophilic bacillus sp. Brazilian Journal of Microbiology, 35(1-2), 91-96. doi:10.1590/S151783822004000100015

Dommel, M. K., Luecking, G., Scherer, S., \& Ehling-Schulz, M. (2011). Transcriptional kinetic analyses of cereulide synthetase genes with respect to growth, sporulation and emetic toxin production in Bacillus cereus. Food Microbiology, 28(2, SI), 284290. doi:10.1016/j.fm.2010.07.001

Ehling-Schulz, M., Fricker, M., \& Scherer, S. (2004). Bacillus cereus, the causative 
agent of an emetic type of food-borne illness. Molecular Nutrition \& Food Research, 48(7), 479-487. doi:10.1002/mnfr. 200100055

European Food Safety Agency. (2005). Bacillus cereus and other bacillus spp. in foodstuffs. EFSA Journal, 175, 1-48.

Finlay, W. J. J., Logan, N. A., \& Sutherland, A. D. (2000). Bacillus cereus produces most emetic toxin at lower temperatures. Letters in Applied Microbiology, 31(5), 385-389. doi:10.1046/j.1472-765x. 2000.00835.x

Finlay, W. J. J., Logan, N. A., \& Sutherland, A. D. (2002a). Bacillus cereus emetic toxin production in cooked rice. Food Microbiology, 19(5), 431-439. doi:10.1006/yfmic.505

Finlay, W. J. J., Logan, N. A., \& Sutherland, A. D. (2002b). Bacillus cereus emetic toxin production in relation to dissolved oxygen tension and sporulation. Food Microbiology, 19(5), 423-430. doi:10.1006/yfmic.504

From, C., Pukall, R., Schumann, P., Hormazabal, V., \& Granum, P. E. (2005). Toxinproducing ability among bacillus spp. outside the Bacillus cereus group. Applied and Environmental Microbiology, $71(3), 1178$ 1183. doi:10.1128/AEM.71.3.1178-1183. 2005

Granum, P. E. (2007). Food microbiology: Fundamentals and frontiers, third edition. In M. P. Doyle \& L. R. Beuchat (Eds.), (Chap. Bacillus cereus, pp. 445456). doi:10.1128/9781555815912

Granum, P. E., \& Lund, T. (1997). Bacillus cereus and its food poisoning toxins. Fems Microbiology Letters, 157(2), 223228. doi:10 . $1111 /$ j. 1574 - 6968 . 1997. tb12776.x

Guerin, A., Ronning, H. T., Dargaignaratz, C., Clavel, T., Broussolle, V., Mahillon, J., ... Nguyen-The, C. (2017). Cereulide production by bacillus weihenstephanensis strains during growth at different ph values and temperatures. Food Microbiology, 65, 130 135. doi:10.1016/j.fm.2017.02.006

Haggblom, M. M., Apetroaie, C., Andersson, M. A., \& Salkinoja-Salonen, M. S. (2002). Quantitative analysis of cereulide, the emetic toxin of Bacillus cereus, produced under various conditions. Applied and Environmental Microbiology, 68(5), 24792483. doi:10.1128/AEM.68.5.2479-2483. 2002

Jaaskelainen, E. L., Haggblom, M. M., Andersson, M. A., \& Salkinoja-Salonen, M. S. (2004). Atmospheric oxygen and other conditions affecting the production of cereulide by Bacillus cereus in food. International Journal of Food Microbiology, 96(1), 7583. doi:10.1016/j.ijfoodmicro.2004.03.011

Jay, J. M. (1996). Modern food microbiology (5. ed. New York: Chapman \& Hall, Eds.). doi:10.1007/978-1-4615-7476-7

Jay, J. M., Loessner, M. J., \& Golden, D. A. (2005). Modern food microbiology. In I. New York USA: Springer Science \pm Business media (Ed.), (Chap. Bacillus cereus gastroenteritis, pp. 583-590).

Kramer, J. M., \& Gilbert, R. J. (1989). Bacillus cereus and other bacillus species. Foodborne Bacterial Pathogens, 19, 21-70.

Lindsay, D., Brozel, V. S., Mostert, J. F., \& von Holy, A. (2000). Physiology of dairyassociated bacillus spp. over a wide ph range. International Journal of Food $M i$ crobiology, 54(1-2), 49-62. doi:10.1016/ S0168-1605(99)00178-6

Lund, T., De Buyser, M. L., \& Granum, P. E. (2000). A new cytotoxin from Bacillus cereus that may cause necrotic enteritis. Molecular Microbiology, 38(2), 254-261. doi:10.1046/j.1365-2958.2000.02147.x

Martinez, S., Borrajo, R., Franco, I., \& Carballo, J. (2007). Effect of environmental parameters on growth kinetics of Bacillus cereus (atcc 7004) after mild heat treatment. International Journal of Food Microbiology, 117(2), 223-227. doi:10.1016/j . pestbp . 2006.08 .002

McKillip, J. L. (2000). Prevalence and expression of enterotoxins in Bacillus cereus and other bacillus spp., a literature review. $A n$ tonie Van Leeuwenhoek International Journal of General and Molecular Microbiology, r7(4), 393-399. doi:10 . 1023 / A : 1002706906154

Mikami, T., Horikawa, T., Murakami, T., Matsumoto, T., Yamakawa, A., Murayama, S., ... Suzuki, M. (1994). An improved 
method for detecting cytostatic toxin (emetic toxin) of Bacillus cereus and its application to food samples. Fems Microbiology Letters, $119(1-2), 53-57$.

Nguyen-The, C., Carlin, F., \& Guinebretière, M. H. (2003). Bacillus cereus and food safety. Bulletin of the Societe Francaise de Microbiologie, 18, 104-112. Retrieved from https:// www.sfm-microbiologie . org / wp - content / uploads / 2019 / 10 / SFM_Bull2003_P104-112.pdf

Pielaat, A., Fricker, M., Nauta, M. J., \& Van Leusden, F. M. (2005). Biodiversity in Bacillus cereus. National Institute for Public Health and the Environment, The Netherlands. RIVM rapport 250912004.

Pirttijärvi, T. S. M., Andersson, M. A., Scoging, A. C., \& Salkinoja-Salonen, M. S. (1999). Evaluation of methods for recognising strains of the bacillus cereus group with food poisoning potential among industrial and environmental contaminants. Systematic and Applied Microbiology, 22(1), 133144. doi:10.1016/S0723-2020(99)80036-8

Rajkovic, A., Uyttendaele, M., Ombregt, S. A., Jaaskelainen, E., Salkinoja-Salonen, M., \& Debevere, J. (2006). Influence of type of food on the kinetics and overall production of Bacillus cereus emetic toxin. Journal of Food Protection, 69(4), 847-852. doi:10 . 4315/0362-028X-69.4.847

Shaheen, R., Andersson, M. A., Apetroaie, C., Schulz, A., Ehling-Schulz, M., Ollilainen, V. M., \& Salkinoja-Salonen, M. S. (2006). Potential of selected infant food formulas for production of Bacillus cereus emetic toxin, cereulide. International Journal of Food Microbiology, 107(3), 287-294. doi:10. 1016/j.ijfoodmicro.2005.10.007

Thorsen, L., Budde, B. B., Henrichsen, L., Martinussen, T., \& Jakobsen, M. (2009). Cereulide formation by bacillus weihenstephanensis and mesophilic emetic Bacillus cereus at temperature abuse depends on pre-incubation conditions. International Journal of Food Microbiology, 134 (1-2, SI), 133-139. Food Micro 2008 Conference, Aberdeen, SCOTLAND, SEP 01-04, 2008. doi:10.1016/j.ijfoodmicro.2009.03.023
Turnbull, P. C. B. (1996). Bacillus (B. S. et al., Ed.). Baron's Medical Microbiology. (4th ed.). University of Texas Medical Branch.

Wijnands, L. M., Dufrenne, J. B., Rombouts, F. M., In't Veld, P. H., \& Van Leusden, F. M. (2006). Prevalence of potentially pathogenic Bacillus cereus in food commodities in the netherlands. Journal of Food Protection, 69(11), 2587-2594. doi:10. 4315/0362-028X-69.11.2587

Wong, H. C., \& Chen, Y. L. (1988). Effects of lactic-acid bacteria and organic-acids on growth and germination of Bacillus cereus. Applied and Environmental Microbiology, 54 (9), 2179-2184.

Yokoyama, K., Ito, M., Agata, N., Isobe, M., Shibayama, K., Horii, T., \& Ohta, M. (1999). Pathological effect of synthetic cereulide, an emetic toxin of bacillus cereus, is reversible in mice. Fems Immunology and Medical Microbiology, 24(1), 115-120. doi:10 . 1016 / S0928 - 8244(99) 00017-6 